\title{
Selection of Suitable Endogenous Reference Genes for Relative Copy Number Detection in Sugarcane
}

\author{
Bantong Xue ${ }^{1, \dagger}$, Jinlong Guo ${ }^{1, \dagger}$, Youxiong Que ${ }^{1}$, Zhiwei Fu ${ }^{1}$, Luguang Wu ${ }^{2}$ and Liping Xu ${ }^{1, *}$
}

1 Key Laboratory of Sugarcane Biology and Genetic Breeding, Fujian Agriculture and Forestry University, Ministry of Agriculture, Fuzhou 350002, China; E-Mails: xuebantong@163.com (B.X.); j1.guo@163.com (J.G.); queyouxiong@hotmail.com (Y.Q.); fuzhiwei1991@126.com (Z.F.)

2 School of Agriculture and Food Sciences, University of Queensland, Brisbane, QLD 4072, Australia; E-Mail: 1.wu@uq.edu.au

$\dagger$ These authors contributed equally to this work.

* Author to whom correspondence should be addressed; E-Mail: xlpmail@126.com; Tel.: +86-591-8377-2604; Fax: +86-591-8385-1742.

Received: 19 February 2014; in revised form: 20 April 2014 / Accepted: 7 May 2014 / Published: 19 May 2014

\begin{abstract}
Transgene copy number has a great impact on the expression level and stability of exogenous gene in transgenic plants. Proper selection of endogenous reference genes is necessary for detection of genetic components in genetically modification (GM) crops by quantitative real-time PCR (qPCR) or by qualitative PCR approach, especially in sugarcane with polyploid and aneuploid genomic structure. qPCR technique has been widely accepted as an accurate, time-saving method on determination of copy numbers in transgenic plants and on detection of genetically modified plants to meet the regulatory and legislative requirement. In this study, to find a suitable endogenous reference gene and its real-time PCR assay for sugarcane (Saccharum spp. hybrids) DNA content quantification, we evaluated a set of potential "single copy" genes including P4H, APRT, ENOL, CYC, TST and $P R R$, through qualitative PCR and absolute quantitative PCR. Based on copy number comparisons among different sugarcane genotypes, including five $S$. officinarum, one $S$. spontaneum and two $S$. spp. hybrids, these endogenous genes fell into three groups: ENOL-3 - high copy number group, TST-1 and PRR-1-medium copy number group, P4H-1, APRT-2 and CYC-2-low copy number group. Among these tested genes, P4H, $A P R T$ and $C Y C$ were the most stable, while ENOL and TST were the least stable across different sugarcane genotypes. Therefore, three primer pairs of P4H-3, APRT-2 and CYC-2
\end{abstract}


were then selected as the suitable reference gene primer pairs for sugarcane. The test of multi-target reference genes revealed that the $A P R T$ gene was a specific amplicon, suggesting this gene is the most suitable to be used as an endogenous reference target for sugarcane DNA content quantification. These results should be helpful for establishing accurate and reliable qualitative and quantitative PCR analysis of GM sugarcane.

Keywords: sugarcane; endogenous reference gene; absolute quantification; copy number

\section{Introduction}

Sugarcane (Saccharum spp. hybrids) is the world's largest crop, accounting for $80 \%$ of all sugar produced in the world, cultivated in 101 countries and the cultivated area was about 26.1 million hectares in 2012 according to the FAO estimates, with a worldwide harvest of 1.83 billion tons. Sugarcane, accumulating large quantities of sucrose in stem tissues, is one of the most important sugar crops and has also been developed into an important energy crop [1]. It has proved very difficult to obtain a multi-merits sugarcane variety with high biomass, high sugar content and excellent disease and pest resistance by relying solely on traditional hybridization using asexually reproduced modern sugarcane varieties, which is a complex of $S$. officinarum (chromosome number 80 ), S. spontaneum (chromosome number from 40 to 128) and even containing Erianthus arundinaceum in sugarcane clones bred in recent five years in China, with a complex allopolyploid and aneuploid genetic background [2]. Genetic transformation has a potential to introduce desirable traits into target crops and to supplement traditional plant breeding techniques [3], resulting in a revolution in sugarcane breeding and sucrose production [4]. Sugarcane has several advantages that make it an ideal candidate for improvement via genetic engineering. It is rarely flowering and producing fewer viable seeds from commercial sugarcane cultivars especially in the commercial cultivation, which greatly reduces the potential of genetic drifting from genetically modified (GM) sugarcane. Unlike other GM food crops, GM sugarcane could be easily accepted by the public and regulatory authorities, as refined white sugar is the most chemically pure food derived from plants and has been found to be free from DNA and proteins expressed from the introduced transgene [5]. Along with the first sugarcane transgene event released for commercial cultivation in 2013, the establishment of detection technology for transgenic components of sugarcane source has become necessary and urgent. When referring to transgene breeding, the agronomic and economic characters of transgenic sugarcane can be affected by a number of factors, including but not confined to the site of insertion, the direction of adjacent transgenic elements and gene copy number. Higher copies in transgenic sugarcane can even cause co-suppression, mainly from transcriptional gene silencing (TGS) or post-transcriptional gene silencing (PTGS) [6,7]. Agrobacterium-mediated and particle bombardment are the two methods widely used in sugarcane genetic transformation [8,9]. However, Agrobacterium-mediated transformation is not as successful as that by gene gun bombardment in sugarcane. Consequently most transgenic sugarcane events have been produced by the latter technique and tend to show high copy numbers of recombinant inserts [10]. Besides, even though fewer copies of recombinant inserts are obtained in transgenic sugarcane via Agrobacterium-mediated transformation, it may still contain two or more copies of the recombinant 
inserts. To accelerate the application of transformation in sugarcane, it is necessary and urgent to identify endogenous reference genes for transgenic sugarcane detection.

Different molecular techniques such as Southern blotting [10], multiplex probe amplification and hybridization and microarray analysis [11] have been used to explore the gene copy number in transgenic plants. Although routinely applied and reliable, these methods are labor-intensive, time-consuming, and require considerable amounts of DNA. In addition, they produce inaccurate estimation of the foreign gene copy number and may involve the use of hazardous radioisotopes. The abovementioned disadvantages rank these methods as impractical on a large scale screening of transgenic plants in early stages $[3,11,12]$. Moreover, Southern blotting does not accurately reflect the presence of rearranged copy numbers when relevant restriction sites are lacking [13]. These techniques are even harder in the sugarcane hybrid due to the complicated genome of 10 to $12 \mathrm{~Gb}$ [14] and 3.05-8.91 pg/2C [15]. In addition, sugarcane transgenic breeding needs a transformation population for selection of plants with the ideal phenotypes. Therefore, the method with high-throughput and with the capability to estimate high transgene copy numbers should be an ideal complementary to the other methods such as Southern blotting.

To overcome those limitations, a fast, sensitive and effective method has been developed for estimating transgene copy number by quantitative real-time PCR technique (qPCR) [12,16-18]. This method can trace the amplification of a target DNA sequence by monitoring fluorescence emitted from specific double-stranded DNA binding dyes or the fluorophore-labeled during the process of reaction $[3,12,19]$. In addition, it is valuable for the detection of rearrangements between two transgenic plant lines. There are mainly two kinds of qPCR assays in use: relative quantification [15,20] and absolute quantification [21]. Though both approaches were developed for relative copy number estimates, the former is based on a ratio between two targets while the latter quantifies an unknown amount of target towards a standard curve for the same target [22,23]. So far, qPCR has been employed to detect transgene copy number in several plant species, such as Nicotiana tabacum [24], Brassica napus [25], Zea mays hybrids [20], Oryza sativa spp. [26], Gossypium spp. [27] and Solanum lycopersicum [15].

A sensitive and reliable endogenous reference gene is essential for species differentiation, and for detection of genetically modified organism (GMO) products in transgenic plants [28]. The endogenous reference genes should be stable among cultivars and show a low copy number (ideally but not indispensable single copy) in the haploid genome [16], species-specific due to the need to determine the species source of the detection samples, especially when the detection samples are plant processed product, such as food. For sugarcane, the "single copy" means "a gene that exists as a single copy per haploid genome". More specifically, due to the estimated ploidy (8) of sugarcane, single cell copy number of a certain candidate gene should be divided by 8 , thus, a future value less than 1 means the target gene detected presents a single copy per haploid genome. To date, the corresponding endogenous reference genes have been developed in several crops, such as Lectin and $\beta$-actin for Glycine max [29], hmga gene for Z. mays [30], PEP [31] and HMGI/Y [32] for B. napus, LAT52 for Lycopersicon esculentum [33] and SPS for O. saliva [31]. However, the increased number of reported endogenous reference genes has made it difficult to select the best candidate for a specific GMO analysis, and how to harmonize these endogenous reference genes is becoming not only important but also necessary in some cases. To our knowledge, there is only the publication by Casu et al. [1] focused on endogenous reference genes for sugarcane. It relies on the reference gene sequences derived from Sorghum bicolor, suggesting that there is still a lack of relatively stable endogenous reference 
genes for detection of transgenic products as an internal positive control in sugarcane, and highlighting the necessity of selection of endogenous reference genes for transgenic sugarcane detection.

To find out low copy genes with small copy number variation among different sugarcane genotypes, six potential endogenous genes, $P 4 H, A P R T, E N O L, C Y C, T S T$ and $P R R$, were assessed in the present study for their suitability in qPCR. After preliminary validation of the copy numbers of the above genes, those appearing to be low copy numbers were selected for construction of the vector to obtain a multi-target reference plasmid for further test in the same background. The results presented in this paper will help further efforts to quantify DNA content or copy number, contributing to the advance of sugarcane genetic engineering and its commercial application.

\section{Results}

\subsection{Assessment of Primer Within-Species-Specificity}

\subsubsection{Assessment of Primer Within-Species-Specificity by PCR}

Nineteen specific primer pairs were designed for six candidate reference genes (Table 1), each of which was tested for single fragment gene amplification in the preliminary experiments of PCR, using the genomic DNA, isolated from sugarcane cultivar ROC22 and Badila, as templates. Ideal primer pairs were selected if their use through PCR resulted in a single band present on the gel for both ROC22 and Badila with clear background, indicating that the primers were specific to that gene only. After gel electrophoresis, gel purification, sequencing and alignment of the amplified fragments, a total of ten primer pairs were selected based on the above selection criterion for subsequent qPCR. Experiments were conducted as: $\mathrm{P} 4 \mathrm{H}-1$ and $\mathrm{P} 4 \mathrm{H}-3$ corresponding to the gene $P 4 H$, ENOL-3 to the gene ENOL, TST-1 and TST-3 to the gene TST, APRT-1 and APRT-2 to the gene APRT, CYC-1 and CYC-2 to the gene CYC and PRR-1 to the gene PRR, respectively (Table 1, Figure 1).

\subsubsection{Assessment of Primer Performance by qPCR}

Standard curves of the above ten selected primer pairs were established respectively to evaluate the amplification efficiency, and melting curves were used to check the within-species-specificity of each qPCR reactions. An ideal reaction reaches an $E$ value close to 1.0, representing a PCR efficiency of $100 \%$ [19,26-28]. The data in Table 2 indicated that the $R^{2}$ values of the nine primer sets for the standard curves were $>0.989$ and the estimated amplification efficiencies $(E)$ were between 0.926 and 1.200, except for the primer set of CYC-1 (Table 2). A single sharp peak in each of the dissociation curves, which corresponds to each of the primer sets, indicated a single melting event, and thus represents a single amplification product, but one which might arise from repeats within the sugarcane genome. In this context, the primer pairs P4H-3, APRT-2, CYC-2 and TST-1 were superior to P4H-1, APRT-1, CYC-1 and TST-3, respectively, based on their melting curves (Supplementary Figure S1). The same results were also verified on the sugarcane cultivars Saccharum spp. hybrids ROC22 (data not shown). These observations resulted in the primer pairs P4H-3, APRT-2, CYC-2, TST-1, ENOL-3 and PRR-1 being selected for the development of the qPCR assay. 
Table 1. Primers used in the present study.

\begin{tabular}{|c|c|c|c|c|}
\hline Gene & Primer pair \# & Primer sequence & $\begin{array}{l}\text { Product } \\
\text { size/bp }\end{array}$ & $\begin{array}{c}\text { Source } \\
\text { sequence ID }\end{array}$ \\
\hline \multirow{6}{*}{$P 4 H$} & \multirow[t]{2}{*}{ P4H-1* } & F: 5'-GCGACATCAGAACAGTGTGAA-3' & 100 & \multirow[t]{2}{*}{ sb01g007280* } \\
\hline & & R: 5'-TTGTACTCTCCGCGGTTTCT-3' & & \\
\hline & \multirow[t]{2}{*}{ P4H-2 } & F: 5'-GTCCGTAATCCCATACCAGATTTT-3' & 80 & \multirow{4}{*}{$\begin{array}{l}\text { CA107003, } \\
\text { CA106927, } \\
\text { CA209790, } \\
\text { CA131236 }\end{array}$} \\
\hline & & R: 5'-CACACTGTTCTGATGTCGCAAA-3' & & \\
\hline & \multirow[t]{2}{*}{ P4H-3 } & F: 5'-GTGAAAATATAGTAAAAACTGCGAAGGA-3' & \multirow[t]{2}{*}{84} & \\
\hline & & R: 5'-TTGTACTCTCCGCGGTTTCTC-3' & & \\
\hline \multirow{6}{*}{ ENOL } & \multirow[t]{2}{*}{ ENOL-1* } & F: 5'-TCCTTACAAAGGATGGGAGC-3' & 96 & \multirow[t]{2}{*}{$\mathrm{sb} 02 \mathrm{~g} 023480 *$} \\
\hline & & R: 5'-TGTACAGATCACCCAGACGC-3' & & \\
\hline & \multirow[t]{2}{*}{ ENOL-2 } & F: 5'-TTTTGATCAGGATGACTGGAGTTC-3' & 75 & \multirow{4}{*}{$\begin{array}{l}\text { CA229198, } \\
\text { CA131106 }\end{array}$} \\
\hline & & R: 5'-AAATCATCACCCACAATTTGGAT-3' & & \\
\hline & \multirow[t]{2}{*}{ ENOL-3 } & F: 5'-GGACCCTTTTGATCAGGATGAC-3' & \multirow[t]{2}{*}{80} & \\
\hline & & R: 5'-AATCATCACCCACAATTTGGATATC-3' & & \\
\hline \multirow{12}{*}{$T S T$} & \multirow[t]{2}{*}{ TST-1* } & F: 5'-ACATGCTGCCATCTGAAAAG-3' & 95 & \multirow[t]{2}{*}{$\operatorname{sb} 08 g 020860^{*}$} \\
\hline & & R: 5'-CAGCCCCTTTCCATCATAAA-3' & & \\
\hline & \multirow[t]{2}{*}{ TST-2 } & F: 5'-GCTGTTCAGTGCTGCTCGTGTT-3' & 81 & \multirow{10}{*}{$\begin{array}{l}\text { ca182497, } \\
\text { ca095999, } \\
\text { ca251048, } \\
\text { ca176811, } \\
\text { ca076277, } \\
\text { cf575388, } \\
\text { ca085087, } \\
\text { ca205081, } \\
\text { ca074129, } \\
\text { ca076192 }\end{array}$} \\
\hline & & R: 5'-GGCAAACCTCCATCTAACACCC-3' & & \\
\hline & \multirow[t]{2}{*}{ TST-3 } & F: 5'-TCAGTGCTGCTCGTGTTTGGT-3' & 130 & \\
\hline & & R: 5'-ATGGCATCACTGGAGGCACTT-3' & & \\
\hline & \multirow[t]{6}{*}{ TST-4 } & F: 5'-AAGTGCCTCCAGTGATGCCA-3' & 200 & \\
\hline & & R: 5'-ACCTGAGGAAACGGAACGCA-3' & & \\
\hline & & & & \\
\hline & & & & \\
\hline & & & & \\
\hline & & & & \\
\hline \multirow{7}{*}{$A P R T$} & \multirow[t]{2}{*}{ APRT-1* } & F: 5'-TGACACATTCCCAACCTCAA-3' & 119 & \multirow[t]{2}{*}{ sb02g033370* } \\
\hline & & R: 5'-ATCTCTCTCCCTGAGTGGCA-3' & & \\
\hline & \multirow[t]{5}{*}{ APRT-2 } & F: 5'-AGGGAAGTGGTTCGGTGATG-3' & 74 & CA089504, \\
\hline & & R: 5'-TGATAAAGAGCACATGAACCAACA-3' & & CA089592, \\
\hline & & & & CA146761, \\
\hline & & & & CA150154, \\
\hline & & & & \\
\hline & CYC-1* & F:5'-CTCATGGAAAACTTACCGGG-3' & 95 & sb10g030790* \\
\hline & & R:5'-TGCATCCAGCAAGAAAGTTG-3' & & \\
\hline & CYC-2 & F:5'-ACTGATGACATTCCCTTGCCTAT-3' & 226 & ca176931, \\
\hline & & R:5'-CCGACAGCATAGGCAAGGGA-3' & & ca235106, \\
\hline & CYC-3 & R:5'-ATAGTCAACCACAGCCAGGGA-3' & 114 & ca256302, \\
\hline CYC & & F:5'-AACCAACCTACGGTTGCCCA-3' & & ca101120, \\
\hline & & & & bu103284, \\
\hline & & & & ca289292, \\
\hline & & & & ca074749, \\
\hline & & & & ca253051, \\
\hline & & & & ca126707 \\
\hline
\end{tabular}


Table 1. Cont.

\begin{tabular}{|c|c|c|c|c|}
\hline Gene & Primer pair \# & Primer sequence & $\begin{array}{c}\text { Product } \\
\text { size/bp }\end{array}$ & $\begin{array}{c}\text { Source } \\
\text { sequence ID }\end{array}$ \\
\hline \multirow{8}{*}{$P R R$} & \multirow[t]{2}{*}{ PRR-1* } & F: 5'-GCCAAATTCAGGCAGAAAAG-3' & 93 & \multirow[t]{2}{*}{ sb04g026190* } \\
\hline & & R: 5'-CACCCTAGGCCTTGTTTCAG-3' & & \\
\hline & \multirow[t]{2}{*}{ PRR-2 } & F: 5'-GCACCACCCTCCTCTCAGAC-3' & 261 & \multirow{6}{*}{$\begin{array}{l}\text { ca275375, } \\
\text { ca297639, } \\
\text { ca134882, } \\
\text { ca246262, } \\
\text { ca245313, } \\
\text { ca } 083303\end{array}$} \\
\hline & & R: 5'-AATGAGCTGGTGGTTGGGGT-3' & & \\
\hline & \multirow[t]{2}{*}{ PRR-3 } & F: 5'-ACCAATAGCACCACCCTCCTC-3' & 239 & \\
\hline & & R: 5'-GACGACCCAGCAACCCTCAG-3' & & \\
\hline & \multirow[t]{2}{*}{ PRR-4 } & F: 5'-ACCAATAGCACCACCCTCCTC-3' & 239 & \\
\hline & & R: 5'-GACGACTCAGCAATCCTCAG-3' & & \\
\hline
\end{tabular}

Marked with * indicates primer pairs reported in literature [1], while without * are primers redesigned based on the sequences of sugarcane ESTs; P4H: prolyl 4-hydroxylase, ENOL: enolase, TST: thiosulfate sulfur transferase, APRT: anthranilate phosphoribosyl transferase, CYC: cyclin, PRR: pseudo response regulator.

Figure 1. PCR amplification products of potential reference genes. (a) ROC22; (b) Badila; M 100 bp Marker, 1 P4H-1, 2 P4H-2, 3 P4H-3, 4 ENOL-1, 5 ENOL-2, 6 ENOL-3, 7 TST-1, 8 TST-2, 9 TST-3, 10 TST-4, 11 APRT-1, 12 APRT-2, 13 CYC-1, 14 CYC-2, 15 CYC-3, 16 PRR-1, 17 PRR-2, 18 PRR-3, 19 PRR-4, M 50 bp Marker, white arrows indicated the nine potential reference primer pairs which were unsuitable for further evaluation. On that gel an arrow would have been added to lane 14 but with other shown gels are not shown, therefore it was also selected.

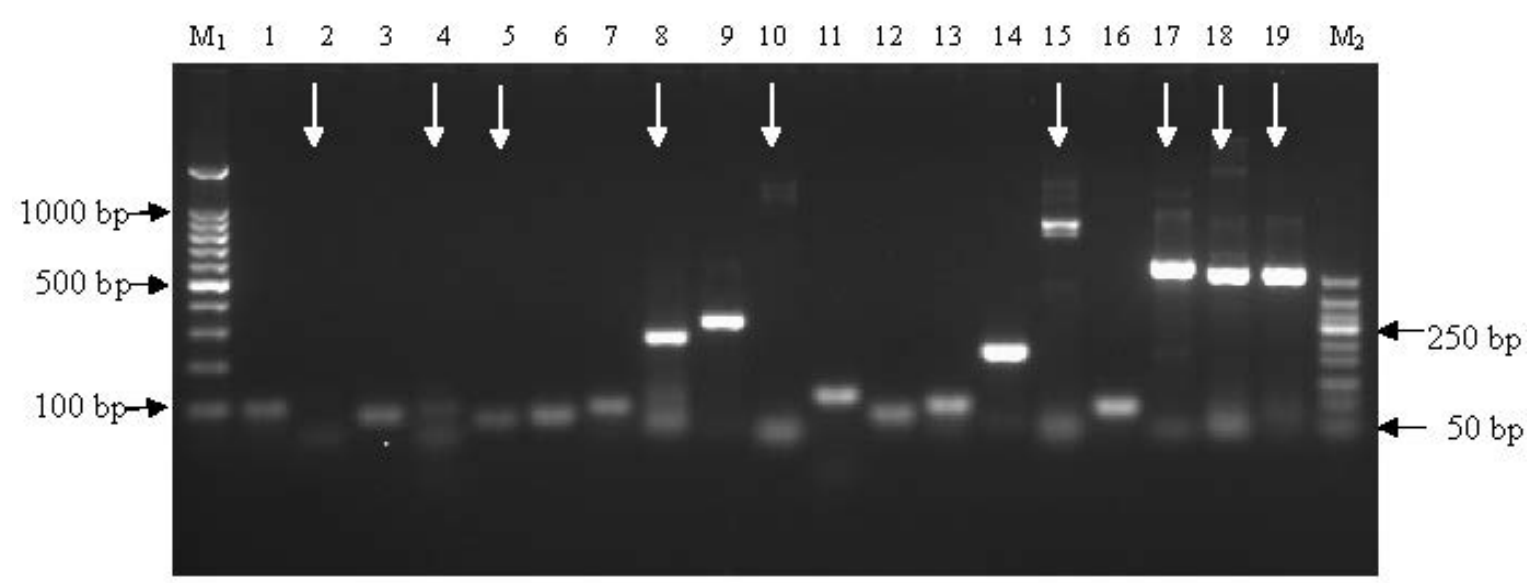

(a)

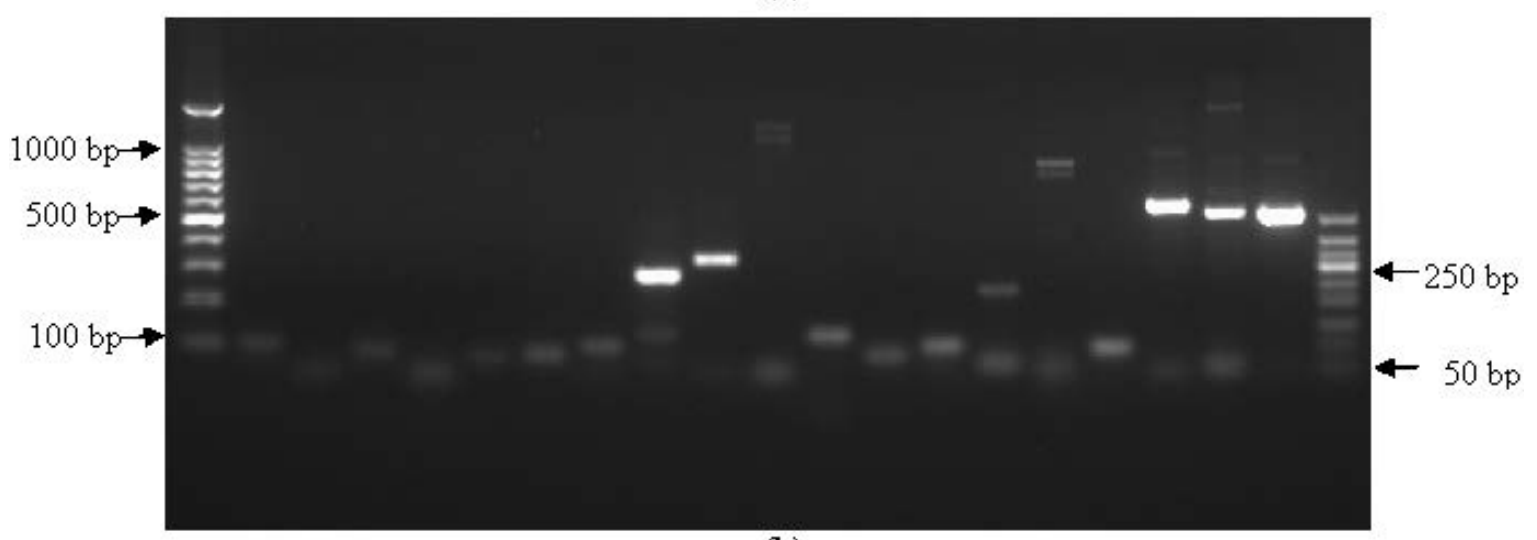

(b) 
Table 2. The standard curve formula, coefficient of determination $\left(R^{2}\right)$ and PCR amplification efficiency $(E)$ performed in qPCR assays.

\begin{tabular}{|c|c|c|c|c|}
\hline Gene & $\begin{array}{c}\text { Primer } \\
\text { pairs }\end{array}$ & Standard curve formula & $R^{2}$ & $E$ \\
\hline & & ROC22 Badila & ROC22 Badila & ROC22 Badila \\
\hline \multirow{2}{*}{$P 4 H$} & P4H-1 & $y=-3.212 x+35.610 y=-3.051 x+35.328$ & 0.9890 .996 & 1.0481 .127 \\
\hline & $\mathrm{P} 4 \mathrm{H}-3$ & $y=-3.275 x+37.509 y=-3.194 x+36.323$ & 0.9980 .993 & 1.0201 .056 \\
\hline \multirow{2}{*}{$A P R T$} & APRT-1 & $y=-3.174 x+35.962 y=-2.918 x+34.326$ & 0.9960 .994 & 1.0661 .200 \\
\hline & APRT-2 & $y=-3.328 x+37.704 y=-3.202 x+39.339$ & 0.9980 .999 & 0.9981 .053 \\
\hline \multirow{2}{*}{$C Y C$} & CYC-1 & $y=-2.321 x+32.405 y=-2.218 x+37.622$ & 0.9550 .816 & 1.6971 .824 \\
\hline & CYC-2 & $y=-3.047 x+34.961 y=-3.159 x+37.622$ & 0.9920 .998 & 1.1291 .073 \\
\hline \multirow{2}{*}{$T S T$} & TST-1 & $y=-3.272 x+38.265 y=-3.402 x+39.975$ & 0.9940 .999 & 1.0210 .968 \\
\hline & TST-3 & $y=-3.161 x+37.308 y=-3.410 x+38.854$ & 0.9990 .999 & 1.0720 .965 \\
\hline ENOL & ENOL-3 & $y=-3.214 x+37.237 y=-3.403 x+44.813$ & 0.9990 .999 & 1.0470 .967 \\
\hline PRR & PRR-1 & $y=-3.185 x+35.916 y=-3.514 x+40.872$ & 0.9960 .995 & 1.0610 .926 \\
\hline
\end{tabular}

\subsection{Screening for Low Copy Genes}

\subsubsection{Copy Number Calculation of the Candidate Reference Genes}

Copy number calculation of the candidate reference genes in the genomic DNA of ROC22 and Badila were calculated according to the formula 4.10. Recently, estimated genome sizes of $10 \mathrm{~Gb}$ for ROC22 and of $7.88 \mathrm{~Gb}$ for Badila were reported [34], though the chromosome number and genome size are likely to be quite variable. Based on this assumption, the copy number calculation formula for ROC22 is Copies/genome $=10^{X \mathrm{t}} /\left[25 \times 10^{-9} \mathrm{~g} \times 6.02 \times 10^{23} /\left(10,000(\mathrm{M} \mathrm{bp}) \times 10^{6} \times 660\right)\right]$, while the formula for Badila is Copies/genome $=10^{X \mathrm{t}} /\left[25 \times 10^{-9} \mathrm{~g} \times 6.02 \times 10^{23} /\left(7880(\mathrm{M} \mathrm{bp}) \times 10^{6} \times 660\right)\right]$. Then, an estimated copy number was generated for each gene (Table 3 ). The copy number of these endogenous genes fell into three groups: a high copy number group containing ENOL-3, a medium copy number group including TST-1 and PRR-1, and a low copy number group consist of P4H-3, APRT-2 and CYC-2. The experimental data demonstrated that, in these two varieties, the most stable reference genes were $P 4 H, A P R T$ and $C Y C$ because of the closer copy number, while the least stable genes were $E N O L$ and TST, especially the primer pair ENOL-3 (Table 3). Moreover, three genes P4H, APRT and CYC showed no significant difference in the genomic DNA of ROC22. Similarly, these three genes were not significantly different in Badila. According to these results, primer pairs P4H-3, APRT-2 and CYC-2 were primarily selected as the suitable reference gene primer pairs for further testing. 
Table 3. Estimation of copy number of potential reference primer pairs.

\begin{tabular}{|c|c|c|c|}
\hline \multirow{2}{*}{ Primer pair } & \multirow{2}{*}{ Corresponding gene } & $C$ t value & Copy number \pm SE \\
\hline & & ROC 22 Badila & ROC 22 Badila \\
\hline $\mathrm{P} 4 \mathrm{H}-3$ & $P 4 H$ & 23.25922 .725 & $10.47 \pm 0.04 \mathrm{C} 6.28 \pm 0.36 \mathrm{~B}$ \\
\hline ENOL-3 & ENOL & 21.05024 .220 & $47.68 \pm 0.12$ A $389.26 \pm 1.09 \mathrm{~A}$ \\
\hline TST-1 & $T S T$ & 21.68924 .558 & $51.14 \pm 0.21 \mathrm{~A} 11.76 \pm 0.17 \mathrm{~B}$ \\
\hline APRT-2 & $A P R T$ & 22.95224 .874 & $8.39 \pm 0.27 \mathrm{C} 11.41 \pm 0.55 \mathrm{~B}$ \\
\hline CYC-2 & $C Y C$ & 21.57423 .678 & $11.07 \pm 0.13 \mathrm{C} 9.00 \pm 0.53 \mathrm{~B}$ \\
\hline PRR-1 & PRR & 21.14323 .920 & $19.07 \pm 0.23$ B $23.06 \pm 0.29 \mathrm{~B}$ \\
\hline
\end{tabular}

Capital letters represent significant difference of $1 \%$. Different letters mean significant difference; the same letter indicates no significant difference. SE, standard error.

2.2.2. Stability Analysis of the Selected Endogenous Reference Genes in Different Sugarcane Varieties

Due to the exact genome size and ploidy of modern sugarcane being unknown, it is necessary to verify the stability of selected primers P4H-3, APRT-2 and CYC-2 in more sugarcane genotypes with a different genetic background. Considering the ploidy and chromosome composition of $S$. officinarum and $S$. spontaneum are much clearer than modern sugarcane ( $S$. spp. hybrids), one $S$. spontaneum SES208 and several different genotypes of S. officinarum including Black Cheribon (Yunnan, China), Black Cheribon (Fujian, China), Loethers, LA Purple and Crystalina were chosen for further testing. In addition, modern sugarcane varieties Q117 and YCE05-179 were included, of which Q117 was one of the sugarcane varieties used in the study by Casu et al. (2012) and YCE05-179 was a newly derived sugarcane line with outstanding yield-related traits and disease resistance. The estimated copy numbers for these sugarcane genotypes were listed in Table 4. Results of qPCR from different sugarcane genotypes further proved the endogenous genes $P 4 H, A P R T$ and $C Y C$ were sugarcane-specific in low copy number through several sugarcane cultivars.

Table 4. Estimation of the copy numbers of three endogenous genes in sugarcane with different genetic background.

\begin{tabular}{cccc}
\hline Sugarcane genotype & \multicolumn{3}{c}{ Copy number \pm SE } \\
\cline { 2 - 4 } & $\boldsymbol{P 4 H - P 4 H - 3}$ & APRT-APRT-2 & CYC-CYC-2 \\
\hline Black Cheribon (Yunnan) (Saccharum officinarum) & $3.58 \pm 0.01$ & $4.73 \pm 0.47$ & $4.97 \pm 0.07$ \\
Black Cheribon (Fujian) (S. officinarum) & $7.32 \pm 0.78$ & $9.69 \pm 0.16$ & $9.67 \pm 0.17$ \\
Loethers (S. officinarum) & $6.37 \pm 0.13$ & $9.24 \pm 1.03$ & $10.06 \pm 0.24$ \\
Crystalina (S. officinarum) & $3.18 \pm 0.02$ & $5.03 \pm 0.53$ & $4.28 \pm 0.28$ \\
SES208 (S. spontaneum) & $7.20 \pm 0.66$ & $11.82 \pm 0.24$ & $10.95 \pm 0.16$ \\
LA Purple (S. officinarum) & $4.44 \pm 0.13$ & $7.62 \pm 0.95$ & $6.87 \pm 0.21$ \\
Q117 (S. spp. hybrids) & $20.81 \pm 0.53$ & $22.14 \pm 0.27$ & $28.45 \pm 0.10$ \\
YCE05-179 (S. spp. hybrids) & $21.51 \pm 0.17$ & $13.18 \pm 0.12$ & $21.35 \pm 0.72$ \\
\hline
\end{tabular}

2.2.3. Evaluation of Three Candidate Genes in a Multi-Target Reference Plasmid

In order to evaluate the three candidate endogenous reference genes $P 4 H, A P R T$ and $C Y C$, in a uniform background as well as to overcome the problem of suitable positive plant material and avoid 
differences of DNA extraction, a multi-target reference plasmid, carrying the primer sequences (P4H-3, APRT-2 and CYC-2) corresponding to the above three genes, was constructed and assigned as pMD18-PAC with a size of $3005 \mathrm{bp}$. The three standard curves, which were suitable for analyzing the dosages of $P 4 H, A P R T$ and $C Y C$ genes, were established individually based on the 10-fold dilution with a dosage range of $1.0 \times 10^{6}-1.0 \times 10^{2}$ copies per $\mu \mathrm{L}$. The estimated copy numbers of $P 4 H, A P R T$ and $C Y C$ genes were about 3, 2 and 4 in $S$. spp. hybrid ROC22, and were 2, 2 and 3 in S. officinarum Badila, respectively. Using APRT gene as the internal control, the relative abundance of $P 4 H / A P R T, A P R T / A P R T$ and CYC/APRT were 1.5, 1.0 and 2.0 in ROC22, respectively. Similarly, the corresponding relative abundance values present in $S$. officinarum Badila were 1.0, 1.0 and 1.5, respectively (Table 5).

Table 5. Coefficient of determination $\left(R^{2}\right)$, PCR amplification efficiency $(E)$, copy number and the relative abundance value performed in $\mathrm{qPCR}$ assays.

\begin{tabular}{|c|c|c|c|c|c|c|}
\hline \multirow{2}{*}{ Gene } & \multirow{2}{*}{$R^{2}$} & \multirow{2}{*}{$\boldsymbol{E}$} & \multicolumn{2}{|c|}{ Copy number \pm SE } & \multicolumn{2}{|c|}{ Relative abundance value } \\
\hline & & & \multicolumn{2}{|c|}{ ROC22 Badila } & \multicolumn{2}{|c|}{ ROC22 Badila } \\
\hline$P 4 H$ & 0.999 & 1.040 & $2.91 \pm 0.09$ & $2.12 \pm 0.06$ & 1.5 & 1.0 \\
\hline$A P R T$ & 0.999 & 1.049 & $2.45 \pm 0.09$ & $2.21 \pm 0.13$ & 1.0 & 1.0 \\
\hline$C Y C$ & 0.998 & 1.047 & $4.27 \pm 0.08$ & $3.05 \pm 0.18$ & 2.0 & 1.5 \\
\hline
\end{tabular}

For the technical performance of qPCR, the mean squares of coefficient of determination $\left(R^{2}\right)$ were close to 1.0 for all three genes $P 4 H, A P R T$ and $C Y C$ (Table 5), indicating a good linearity between the initial copy numbers and the fluorescence values $(C t)$. The PCR efficiencies $(E)$ of $P 4 H, A P R T$ and $C Y C$ were all also close to 1.0 (Table 5). Apparently, these three standard curves corresponding to $P 4 H, A P R T$ and $C Y C$ genes established in this study were applicable to quantify the gene dosages in sugarcane ( $S$. spp. hybrids, $S$. officinarum and $S$. spontaneum). At the same time, both $P 4 H$ and $A P R T$ genes showed even lower copies or less dosages compared to CYC in the genomes of ROC22 and Badila, while the relative abundance values of $P 4 H$ and $C Y C$ were higher than that of $A P R T$. These results indicated that the $A P R T$ gene was a specific amplicon within the detection using the primer pairs APRT-2, and thus this gene was assumed to be the most suitable one as an endogenous reference gene in sugarcane.

\section{Discussion}

The innovative points in this study are: Firstly, an endogenous reference gene $A P R T$ was evidenced as the best one in copy numbers detection across a range of eight sugarcane genotypes including $S$. spp. hybrids, S. officinarum and S. spontaneum; Secondly, the primers designed for qPCR are sugarcane-specific (universal in sugarcane genotypes, as the first point above), as all the primers were designed from sugarcane ESTs; Thirdly, a practically useful plasmid was constructed with multi-target genes for qPCR, which resulted in the detection under the same background. Therefore, this study should serve as a solid foundation for establishing an efficient technique to estimate copy numbers of target genes in sugarcane.

Since the first GM plant, an antibiotic-resistant tobacco, was produced in 1982 [35], an increasing number of transgenic plants, including transgenic sugarcane, have been created and produced with 
different desirable traits, such as insect resistance, disease resistance and herbicide resistance [36]. A series of GM sugarcane events were reported, including Basta herbicide resistance sugarcane [37], $S c M V$-CP transgenic sugarcane [38], GAN transgenic sugarcane [39], Hs 1 pro-1 of nematode-resistant transgenic sugarcane [40], and $B t$ transgenic sugarcane [41]. In addition, the first transgenic sugarcane event aimed at improvement of drought resistance was released for commercial cultivation in Indonesia in 2013. Today, it is widely adopted that GM sugarcane is on the way of commercialization in more countries. However, there is still a lack of endogenous reference genes available for transgenic sugarcane detection.

The advances in PCR instrumentation and fluorescence chemistry have made it possible to precisely quantify the specific amplification products [12]. Compared to Southern blotting, multiplex probe amplification and microarray analysis, qPCR can analyze hundreds of samples with a small amount of DNA, and significantly expedite the identification of the single copy or low copies insertion at much earlier stages [3]. Due to its simplicity, sensitivity and specificity, the qPCR assay has been widely used in copy number detection [15,24-27]. To make PCR assay more precise and reliable, and to detect genetically modified organism products as an internal positive control, application of appropriate endogenous reference gene is indispensible [42]. Although a series of endogenous reference genes were developed for diploid plants and/or used for TaqMan probes [43,44], only one case study was found on the assessment of transgene copy number in sugarcane by qPCR [1]. In the present study, we evaluated a set of potential "single copy" genes including P4H, APRT, ENOL, CYC, TST and PRR, for their suitability as endogenous reference genes for transgenic detection in sugarcane. We began on the basis of preliminary estimations, by comparing copy numbers of the above six genes among eight different sugarcane genotypes. We then selected the genes with low copy numbers to construct a plasmid with multi-target reference genes for further tests. With the development of new GM crops, more and more reference plasmids have been employed simultaneously to detect multiple foreign genes [16]. Based on the standard curve which was created with a confirmable size multi-target plasmid, qPCR has been used successfully for determining the mass of gDNA that correspond to copy numbers of target sequences in GMO [45,46]. The qPCR assay established here was specifically designed for sugarcane because the primers in qPCR were designed according to sugarcane ESTs. Moreover, qPCR is currently the most sensitive method and the formula used is exponential, so slight differences can result in a wide bias. The value of endogenous reference genes' copy number in this paper was usually estimated in a range. Thus, increasing the biological and technical replicates is more important for the repeatability of results. More importantly, the selected endogenous reference gene $A P R T$, with the feature of low copies, can be considered as a reliable reference one among various sugarcane genotypes as the primer pairs APRT-2 has been tested in several sugarcane varieties with different genetic background.

\section{Experimental Section}

\subsection{Tissue Samples}

Leaf samples of sugarcane cultivars Saccharum spp. hybrids ROC22 and YCE05-179, S. officinarum Badila and LA Purple and S. spontaneum SES208 were collected from the Key Laboratory of Sugarcane Biology and Genetic Breeding of the Ministry of Agriculture; Leaf samples of sugarcane variety Q117, S. officinarum Black Cheribon (originated from Yunnan, China), Black Cheribon (originated from 
Fujian, China), Loethers and Crystalina were provided by the National Sugarcane Germplasm Nursery, Yunnan, China.

\subsection{Reagents and Consumables}

SYBR Green Master (ROX) was purchased from Roche (Shanghai, China); Plasmid Mini Kit and Gel Extraction Kit from Omega Bio-Tek (Shanghai, China); pMD 18-T vector and Ex Taq from TaKaRa Biotechnology Co., Ltd., (Dalian, China); competent cell DH5 $\alpha$ and DNA Markers from TianGen Biotechnology Co., Ltd., (Beijing, China).

PCR Tubes, PCR Strip Tubes, Optical 96-Well Reaction Plate and other PCR related consumables were from Applied Biosystems (Foster, CA, USA) unless specified.

\subsection{Extraction and Isolation of Genomic DNA}

Genomic DNA was extracted according to the CTAB-based protocol described by Paterson et al. [47]. DNA concentrations were measured using a NanoDrop spectrophotometer (Wilmington, DE, USA) and its quality was verified through electrophoresis in 1.0\% agarose gels on a Amersham Pharmacia EPS301 electrophoresis apparatus (Little Chalfont, Amersham, UK), stained with ethidium bromide, detected on a Bio-Rad Gel imaging system (Hercules, Contra Costa, CA, USA); The quantified DNA was diluted with deionized water to $100 \mathrm{ng} / \mu \mathrm{L}$. All DNA samples were stored at $-20{ }^{\circ} \mathrm{C}$.

\subsection{Primer Design for Candidate Endogenous Reference Genes}

Six primer pairs from putative reference genes, P4H, APRT, ENOL, CYC, TST and PRR, with source DNA sequences from Sorghum bicolor reported by Casu et al. [1], were selected as candidate endogenous reference genes in this study. After alignments to sorghum gene sequences, the corresponding fragments were identified from the sugarcane ESTs by BLASTP application (National Center for Biotechnology Information, Bethesda, MD, USA), an additional 13 specific primer pairs targeted at these six putative reference genes were redesigned according to the sugarcane ESTs by Primer Premier 5 software (PREMIER Biosoft International, Palo Alto, CA, USA). The primers used in this experiment are shown in Table 1.

\subsection{Polymerase Chain Reaction (PCR)}

DNA fragments were amplified by PCR based on $25 \mathrm{ng}$ genomic DNA of sugarcane cultivar ROC22 or Badila. A final volume of $25 \mu \mathrm{L}$ was used, containing $2.5 \mu \mathrm{L} 10 \times$ PCR Buffer, $2.0 \mu \mathrm{L}(2.5 \mathrm{mM})$ of dNTPs, $0.125 \mu \mathrm{L}(5 \mathrm{U} / \mu \mathrm{L})$ Ex Taq polymerase, $1.0 \mu \mathrm{L}(10 \mu \mathrm{mol} / \mathrm{L})$ of each gene-specific forward and reverse primer and $17.375 \mu \mathrm{L} \mathrm{ddH}_{2} \mathrm{O}$. PCR was performed under the following conditions: $98{ }^{\circ} \mathrm{C}$ for $30 \mathrm{~s}$ ( 1 cycle); $98{ }^{\circ} \mathrm{C}$ for $15 \mathrm{~s}, 60{ }^{\circ} \mathrm{C}$ for $15 \mathrm{~s} ; 72{ }^{\circ} \mathrm{C}$ for $15 \mathrm{~s}$ ( 35 cycles). All PCR products were separated by electrophoresis on a 3.0\% agarose gel with an Amersham Pharmacia EPS301 electrophoresis apparatus (Little Chalfont, Amersham, UK) in $1 \times$ TAE buffer. A Bio-Rad Gel imaging system (Hercules, Contra Costa, CA, USA) was used for observation of the electrophoresis products. 


\subsection{Preparation of Recombinant Plasmid}

PCR-amplified fragments were purified with a gel purification kit from Omega Bio-Tek (Shanghai, China) and cloned into the pMD18-T vector from TaKaRa Biotechnology Co., Ltd. (Dalian, China), according to the manufacturer's instructions. The recombinant plasmid was transformed into competent E. coli $(D H 5 \alpha)$ and $100 \mu \mathrm{L}$ of transformed culture was spread onto LB plates containing ampicillin $(50 \mu \mathrm{g} / \mathrm{mL})$, X-gal $(20 \mathrm{mg} / \mathrm{mL})$ and IPTG $(50 \mathrm{mg} / \mathrm{mL})$. Transformed (white) colonies were picked up and processed for plasmid isolation and sequencing. Plasmids were extracted using a Plasmid Omega Bio-Tek Mini kit (Shanghai, China) according to the manufacturer's instructions.

\subsection{Calculation of Plasmid Copy Number}

Plasmid DNA concentration was estimated by measuring the absorbance at $260 \mathrm{~nm}$ as described above. Plasmid copy number was calculated according to the following formula:

Number of copies $($ copies $/ \mu \mathrm{L})=6.02 \times 10^{23}($ copies $/ \mathrm{mol}) \times$ plasmid concentrations $(\mathrm{g} / \mu \mathrm{L}) /$

[number of bases pairs $\times(\mathrm{A} \times 313.2+\mathrm{C} \times 289.2+\mathrm{G} \times 329.2+\mathrm{T} \times 304.2)$ Daltons] [48,49].

\subsection{Real-Time Quantitative PCR}

All qPCR assays were performed on an ABI PRISM 7500 Sequence Detection System (Applied Biosystems, Foster City, CA, USA) in $25 \mu \mathrm{L}$ reaction volume containing $12.5 \mu \mathrm{L}$ of $2 \times$ SYBR Green PCR Master mix (Roche, Shanghai, China), $1.0 \mu \mathrm{L}$ of diluted genomic DNA (25 ng) and $1.0 \mu \mathrm{L}$ $(10 \mu \mathrm{mol} / \mathrm{L})$ each of a gene-specific forward and reverse primer. The following standard PCR reaction conditions were used for all transcripts: $50{ }^{\circ} \mathrm{C} 2 \mathrm{~min} ; 95^{\circ} \mathrm{C} 10 \mathrm{~min} ; 45$ cycles of $95{ }^{\circ} \mathrm{C} 15 \mathrm{~s}, 60{ }^{\circ} \mathrm{C} 1 \mathrm{~min}$; 1 cycle of $95{ }^{\circ} \mathrm{C} 15 \mathrm{~s}, 60{ }^{\circ} \mathrm{C} 15 \mathrm{~s}, 95{ }^{\circ} \mathrm{C} 15 \mathrm{~s}$. The last cycle provided dissociation curves for each sample, allowing for assessment of the specificity of amplification. For each sample test, each PCR reaction had three replicates and the experiment was repeated three times.

\subsection{Establishment of Standard Curve}

Each of the purified plasmid was diluted with sterile deionized water to obtain a standard series from $1.0 \times 10^{8}$ to $1.0 \times 10^{1}$ copies/ $\mu \mathrm{L}$ with each step differing by 10 -fold. It's necessary to suspend well by pipetting 30 times when diluting. Assays of qPCR were performed using $25 \mathrm{ng} / \mu \mathrm{L}$ (working concentration) DNA and water as control, with three replicates. After reaction, the values of threshold cycles are achieved. Each standard curve is established by plotting the threshold cycle $(C \mathrm{t})$ on the $Y$-axis and the natural $\log$ of concentration (copies $/ \mu \mathrm{L}$ ) on the $X$-axis, and the equation $y=k \times x+b$, coefficient of determination $\left(R^{2}\right)$ and percentage of variance in copy numbers were achieved.

\subsection{Copy Number Calculation of Endogenous Reference Genes in Sugarcane}

The copy number for putative reference gene in sugarcane genome DNA can be calculated against its established standard curve. After reaction, the values of threshold cycles are achieved. From the slope of a standard curve, PCR amplification efficiency $(E)$ can be calculated according to the equation as follow [50]: 


$$
E=10^{(-1 / \text { slope })}-1
$$

The total copy number $\left(10^{X t}\right)$ of each endogenous reference gene is calculated by relating the $C \mathrm{t}$ value $\left(Y_{\mathrm{t}}\right)$ to its corresponding standard curve, then the single cell copy number $(n)$ of each endogenous reference gene in the sugarcane samples can be calculated by the following formula:

$$
\begin{gathered}
\text { copies }(n) / \text { genome }=10^{X \mathrm{t}} /\left[25 \times 10^{-9} \mathrm{~g} \times 6.02 \times 10^{23} /\right. \\
\left.\left(\text { genome size of single cell }(\mathrm{M} \mathrm{bp}) \times 10^{6} \times 660\right)\right] .
\end{gathered}
$$

Notes: $25 \times 10^{-9} \mathrm{~g}$ is the amount of DNA template (measured by UV absorption) used in each qPCR reaction system, $6.02 \times 10^{23}$ is Avogadro's constant, the genome size of sugarcane can be determined by flow cytometry [51], and average molecular weight $\left(M_{\mathrm{W}}\right)$ of a DNA base pair is 660 daltons.

\subsection{Construction of Multi-Target Reference Plasmid for Screening Low Copy Genes}

In order to create a reference plasmid containing all the test sequences corresponding to the putative reference genes for further test in the same background, all the tested sequences were synthesized by Sangon Biotech Co., Ltd. (Shanghai, China) and constructed onto the same vector to obtain a multi-target reference plasmid [45]. The standard curve for putative low copy gene sequences is established based on $1.0 \times 10^{6}$ to $1.0 \times 10^{2}$ copies of reference plasmids, and the validated primer pairs in the above experiments were employed for qPCR with templates of $25 \mathrm{ng} / \mu \mathrm{L}$ sugarcane genomic DNA of ROC22 and Badila. In addition, one of the above genes was used as the internal control to calculate the relative abundance values to compare the gene dosage [46]. The relative abundance values of the putative low copy genes were calculated: relative abundance $=$ (copy number of determined genes in sample DNA/copy number of the internal control gene in sample DNA).

\section{Conclusions}

The present study succeeded in selection of endogenous reference genes for transgenic sugarcane detection. The $A P R T$, as an endogenous reference gene, was identified from a set of six putative potential "single copy" ones, $P 4 H, A P R T, E N O L, C Y C, T S T$ and PRR in sugarcane. The primer pair APRT-2, corresponding to the $A P R T$ gene, was screened out from nineteen initial primer pairs that corresponded to the above six reference genes. The selected gene of $A P R T$ was considered as "single copy" based on: (1) low heterogeneity among different sugarcane species; and (2) low copy number. This conclusion was derived from testing on all eight sugarcane genotypes with different genetic background including $S$. officinarum, S. spontaneum and the modern varieties ( $S$. spp. hybrids). In addition, the copy number was calculated based on the comparison to a multi-target gene plasmid standard curve. Therefore, $A P R T$ can be used as a reliable endogenous reference gene; when combined with the developed primer pair, it is suitable for transgenic sugarcane precise detection based on absolute quantification using qPCR, which hopefully will accelerate sugarcane genetic engineering and the commercialization of GM sugarcane. 


\section{Acknowledgments}

This work was supported by National Natural Science Foundation of China (Grant No. 31271782), National High Technology Research and Development Program of China (863 Program) Project (2013AA102604), the earmarked fund for the Modern Agriculture Technology of China (CARS-20) and the 948 Program on the Introduction of International Advanced Agricultural Science and Techniques of the Department of Agriculture (2014-S18).

\section{Author Contributions}

Conceived and designed the experiments: L.X., J.G., Y.Q.; Performed the experiments: B.X., J.G., Z.F.; Analyzed the data: B.X., J.G., L.X.; Wrote the paper: B.X., L.X., J.G., Y.Q.; Revised the paper: L.X., J.G., Y.Q., L.W.; Approved the final version of the paper: L.X.

\section{Conflicts of Interest}

The authors declare no conflict of interest.

\section{References}

1. Casu, R.E.; Selivanova, A.; Perroux, J.M. High-throughput assessment of transgene copy number in sugarcane using real-time quantitative PCR. Plant Cell Rep. 2012, 31, 167-177.

2. Arencibia, A.; Vázquez, R.I.; Prieto, D.; Téllez, D.; Carmona, E.R.; Coego, A.; Hernández, L.; de la riva, G.A.; Selman-Housein, G. Transgenic sugarcane plants resistant to stem borer attack. Mol. Breed. 1997, 3, 247-255.

3. Li, W.; Bin, T.; Guo, W.W. Estimating transgene copy number in precocious trifoliate orange by TaqMan real-time PCR. Plant Cell Tissue Organ Cult. 2012, 109, 363-371.

4. Srikanth, J.; Subramonian, N.; Premachandran, M.N. Advances in transgenic research for insect resistance in sugarcane. Trop. Plant Biol. 2011, 4, 52-61.

5. Lakshmanan, P.; Geijskes, R.J.; Aitken, K.S.; Grof, C.L.P.; Bonnett, G.D.; Smith, G.R. Sugarcane biotechnology: The challenges and opportunities. In Vitro Cell. Dev. Biol.-Plant 2005, 41, 345-363.

6. Vaucheret, H.; Fagard, M. Transcriptional gene silencing in plants: targets, inducers and regulators. Trends Genet. 2001, 17, 29-35.

7. Tang, W.; Newton, R.J.; Weidner, D.A. Genetic transformation and gene silencing mediated by multiple copies of a transgene in eastern white pine. J. Exp. Bot. 2007, 58, 545-554.

8. Dai, S.H.; Zheng, P.; Marmey, P.; Zhang, S.P.; Tian, W.Z.; Chen, S.Y.; Beachy, R.N.; Fauquet, C. Comparative analysis of transgenic rice plants obtained by Agrobacterium-mediated transformation and particle bombardment. Mol. Breed. 2001, 7, 25-33.

9. Travella, S.; Ross, S.M.; Harden, J.; Everett, C.; Snape, J.W.; Harwood, W.A. A comparison of transgenic barley lines produced by particle bombardment and Agrobacterium-mediated techniques. Plant Cell Rep. 2005, 23, 780-789.

10. Arencibia, A.D.; Carmona, E.R.; Tellez, P.; Chan, M.T.; Yu, S.M.; Trujillo, L.E.; Oramas, P. An efficient protocol for sugarcane (Saccharum spp. L.) transformation mediated by Agrobacterium tumefaciens. Transgenic Res. 1998, 7, 213-222. 
11. Lucito, R.; West, J.; Reiner, A.; Alexander, J.; Esposito, D.; Mishra, B.; Powers, S.; Norton, L.; Wigler, M. Detecting gene copy number fluctuation in tumor cells by microarray analysis of genomic representations. Genome Res. 2000, 10, 1726-1736.

12. Song, P.; Cai, C.; Skokut, M.; Kosegi, B.; Petolino, J. Quantitative real-time PCR as a screening tool for estimating transgene copy number in WHISKERS ${ }^{{ }^{M}}$-derived transgenic maize. Plant Cell Rep. 2002, 20, 948-954.

13. Mason, G.; Provero, P.; Vaira, A.M.; Accotto, G.P. Estimating the number of integrations in transformed plants by quantitative real-time PCR. BMC Biotechnol. 2002, 2, 20-30.

14. D’Hont, A.; Grivet, L.; Feldmann, P.; Rao, S.; Berding, N.; Glaszmann, J.C. Characterisation of the double genome structure of modern sugarcane cultivars (Saccharum spp.) by molecular cytogenetics. Mol. Gen. Genet. MGG 1996, 250, 405-413.

15. Edmé, S.J.; Comstock, J.C.; Miller, J.D.; Tai, P.Y.P. Determination of DNA content and genome size in sugarcane. Am. Soc. Sugar Cane Technol. 2005, 25, 1-16.

16. Yang, L.T.; Chen, J.X.; Huang, C.; Liu, Y.H.; Jia, S.R.; Pan, L.W.; Zhang, D.B. Validation of a cotton-specific gene, $\mathrm{Sad} 1$, used as an endogenous reference gene in qualitative and real-time quantitative PCR detection of transgenic cottons. Plant Cell Rep. 2005, 24, 237-245.

17. Schefe, J.H.; Lehmann, K.E.; Buschmann, I.R.; Unger, T.; Funke-Kaiser, H. Quantitative real-time RT-PCR data analysis: Current concepts and the novel "gene expression's CT difference" formula. J. Mol. Med. 2006, 84, 901-910.

18. Li, H.; Lv, X.W.; Wang, J.; Li, J.G.; Yang, H.F.; Qin, Y.C. Quantitative determination of soybean meal content in compound feeds: Comparison of near-infrarded spectroscopy and real-time PCR. Anal. Bioanal. Chem. 2007, 389, 2313-2322.

19. Randhawa, G.J.; Singh, M.; Sharma, R. Validation of ST-LS1 as an endogenous reference gene for detection of $A m A l$ and $c r y l A b$ genes in genetically modified potatoes using multiplex and real time PCR. Am. J. Potato Res. 2009, 86, 398-405.

20. Shou, H.X.; Frame, B.R.; Whitham, S.A.; Wang, K. Assessment of transgenic maize events produced by particle bombardment or Agrobacterium-mediated transformation. Mol. Breed. 2004, 13, 201-208.

21. Shen, H.F.; Qian, B.J.; Yang, L.T.; Liang, W.Q.; Chen, W.W.; Liu, Z.H.; Zhang, D.B. Estimation of the homoplasmy degree for transplastomic tobacco using quantitative real-time PCR. Eur. Food Res. Technol. 2010, 231, 143-150.

22. Sellars, M.J.; Vuocolo, T.; Leeton, L.A.; Coman, G.J.; Degnan, B.M.; Preston, N.P. Real-time RT-PCR quantification of Kuruma shrimp transcripts: A comparison of relative and absolute quantification procedures. J. Biotechnol. 2007, 129, 391-399.

23. Leong, D.T.; Gupta, A.; Bai, H.F.; Wan, G.Q.; Yoong, L.F.; Too, H.P.; Chew, F.T.; Hutmacher, D.W. Absolute quantification of gene expression in biomaterials research using real-time PCR. Biomaterials 2007, 28, 203-210.

24. Bubner, B.; Gase, K.; Baldwin, I.T. Two fold differences are the detection limit for determining transgene copy numbers in plants by real-time PCR. BMC Biotechnol. 2004, 4, doi:10.1186/ 1472-6750-4-14.

25. Weng, H.B.; Pan, A.H.; Yang, L.H.; Zhang, C.M.; Liu, Z.L.; Zhang, D.B. Estimating number of transgene copies in transgenic rapeseed by real-time PCR assay with $H M G I / Y$ as an endogenous reference gene. Plant Mol. Biol. Rep.2004, 22, 289-300. 
26. Yang, L.T.; Ding, J.Y.; Zhang, C.M.; Jia, J.W.; Weng, H.B.; Liu, W.X.; Zhang, D.B. Estimating the copy number of transgenes in transformed rice by real-time quantitative PCR. Plant Cell Rep. 2005, 23, 759-763.

27. Yang, L.T.; Pan, A.H.; Zhang, K.W.; Yin, C.S.; Qian, B.J.; Chen, J.X.; Huang, C.; Zhang, D.B. Qualitative and quantitative PCR methods for event-specific detection of genetically modified cotton Mon1445 and Mon531. Transgenic Res. 2005, 14, 817-831.

28. Huang, H.L.; Cheng, F.; Wang, R.A.; Zhang, D.B.; Yang, L.T. Evaluation of four endogenous reference genes and their real-time PCR assay for common wheat quantification in GMOs detection. PLoS One 2013, 8, e75850.

29. James, D.; Schmidt, A.M.; Wall, E.; Green, M.; Masri, S. Reliable detection and identification of genetically modified maize, soybean and canola by multiplex PCR analysis. J. Agric. Food Chem. 2003, 51, 5829-5834.

30. Hernández, M.; Duplan, M.N.; Berthier, G.; Vaïtilingom, M.; Hauser, W.; Freyer, R.; Pla, M.; Bertheau, Y. Development and comparison of four real-time polymerase chain reaction systems for specific detection and quantification of Zea mays L. J. Agric. Food Chem. 2004, 52, 4632-4637.

31. Yang, L.T.; Guo, J.C.; Zhang, H.B.; Liu, J.; Zhang, D.B. Qualitative and quantitative event-specific PCR detection methods for oxy235 canola based on the 3 integration flanking sequence. J. Agric. Food Chem. 2008, 56, 1804-1809.

32. Demeke, T.; Ratnayaka, I. Multiplex qualitative PCR assay for identification of genetically modified canola events and real-time event specific PCR assay for quantification of the GT73 canola event. Food Control 2008, 19, 893-897.

33. Chaouachi, M.; El Malki, R.; Berard, A.; Romaniuk, M.; Laval, V.; Brunel, D.; Bertheau, Y. Development of a real-time PCR method for the diferential detection and quantification of four solanaceae in GMO analysis: potato (Solanum tuberosum), tomato (Solarium lycopersicum), eggplant (Solanum melongena) and pepper (Capsicum annuum). J. Agric. Food Chem. 2008, 56, 1818-1828.

34. Zhang, J.S.; Nagai, C.; Yu, Q.Y.; Pan, Y.B.; Ayala-Silva, T.; Schnell, R.J.; Comstock, J.C.; Arumuganathan, A.K.; Ming, R. Genome size variation in three Saccharum species. Euphytica 2012, 180, 511-519.

35. Fraley, R.T.; Rogers, S.G.; Horsch, R.B.; Sanders, P.R.; Flick, J.S.; Adams, S.P.; Bittner, M.L.; Brand, L.A.; Fink, C.L.; Fry, J.S.; et al. Expression of bacterial genes in plant cells. Proc. Natl. Acad. Sci.USA 1983, 80, 4803-4807.

36. Kok, E.J.; Kuiper, H.A. Comparative safety assessment for biotech crops. Trends Biotechnol. 2003, 21, 439-444.

37. Faclo, M.C.; Neto, A.T.; Ulian, E.C. Transformation and expression of a gene for herbicide resistance in a Brazilian sugarcane. Plant Cell Rep. 2000, 19, 1188-1194.

38. Yao, W.; Yu, A.L.; Xu, J.S.; Geng, G.L.; Zhang, M.Q.; Chen, R.C. Analysis and identification for transgenic sugarcane of ScMV-CP gene. Mol. Plant Breed. 2004, 2, 13-18.

39. Chen, R.K.; Chen, P.H.; Lin, M.J.; Xue, Z.P. A study on genetic transformation of GAN gene in sugarcane. Acta Agric. Univ. Jiangxiensis 2004, 26, 740-743.

40. Chen, P.H.; Xu, L.P.; Chen, R.K. Construction of expression vector of nematode-resistant gene and transformation of sugarcane. Chin. J. Ecol-Agric. 2004, 12, 57-59. 
41. Wang, J.H.; Cao, G.; Zhang, M.Q. Physiological characteristics of Bt transgenic sugarcane. Chin. J. Trop. Crops 2011, 32, 1864-1867.

42. Xu, W.T.; Bai, W.B.; Guo, F.; Luo, Y.B.; Yuan, Y.F.; Huang, K.L. A papaya-specific gene, papain, used as an endogenous reference gene in qualitative and real-time quantitative PCR detection of transgenic papayas. Eur. Food Res. Technol. 2008, 228, 301-309.

43. Beltrán, J.; Jaimes, H.; Echeverry, M.; Ladino, Y.; López, D.; Duque, M.C.; Chavarriaga, P.; Tohme, J. Quantitative analysis of transgenes in cassava plants using real-time PCR technology. In Vitro Cell. Dev. Biol.-Plant 2009, 45, 48-56.

44. Fan, M.J.; Chen, S.; Kung, Y.J.; Cheng, Y.H.; Bau, H.J.; Su, T.T.; Yeh, S.D. Transgene-specific and event-specific molecular markers for characterization of transgenic papaya lines resistant to Papaya ringspot virus. Transgenic Res. 2009, 18, 971-986.

45. Paterson, A.H.; Brubaker, C.L.; Wendel, J.F. A rapid method for extraction of cotton (Gossypium spp.) genomic DNA suitable for RELP or PCR analsis. Plant Mol. Biol. Rep. 1993, 11, 122-127.

46. Li, H.F.; Li, L.; Zhang, L.J.; Xu, Y.L.; Li, W.F. Standard curve generation of PepT1 gene for absolute quantification using real-time PCR. J. Shanxi Agric. Univ.2010, 30, 332-335.

47. Li, L.; Zhao, C.P.; Li, H.L.; Wu, F.; Zhang, L.H.; Xu, D.M.; Wang, J.S.; Li, H.F. Establishment of the plasmid standard curve generation method for absolute quantification PCR. J. Agric. Biotechnol. 2011, 19, 1157-1162.

48. Lee, C.; Kim, J.; Shin, S.G.; Hwang, S. Absolute and relative qPCR quantification of plasmid copy number in Escherichia coli. J. Biotechnol. 2006, 123, 273-280.

49. Grivet, L.; Arruda, P. Sequence polymorphism from EST data in sugarcane: A fine analysis of 6-phosphogluconate dehydrogenase genes. Genet. Mol. Biol. 2001, 24, 161-167.

50. Li, F.W.; Shao, G.G.; Xing, Z.J.; Ling, C.C.; Xia, W.; Zhang, M. Constuction of the plasmid reference molecule for detection of transgenic Soybean MON89788. Agric. Sci. Technol. 2010, $11,55-58$.

51. Su, C.Q.; Xie, J.J.; Sun, Y.; Peng, Y.F. Construction and application of a reference plasmid suitable for determination of $C P T I$ and $c r y l A$ gene dosages in genetically modified cottons. Acta Agron. Sin. 2011, 37, 1533-1539.

(C) 2014 by the authors; licensee MDPI, Basel, Switzerland. This article is an open access article distributed under the terms and conditions of the Creative Commons Attribution license (http://creativecommons.org/licenses/by/3.0/). 